\title{
Moral Constraints on Gender Concepts
}

\section{N. G. Laskowski ${ }^{1}$}

Accepted: 3 January 2020/Published online: 08 January 2020

(C) Springer Nature B.V. 2020

\begin{abstract}
Are words like 'woman' or 'man' sex terms that we use to talk about biological features of individuals? Are they gender terms that we use to talk about non-biological features e.g. social roles? Contextualists answer both questions affirmatively, arguing that these terms concern biological or non-biological features depending on context. I argue that a recent version of contextualism, floated by Jennifer Saul and defended by Esa Diaz-Leon, doesn't exhibit the right kind of flexibility to capture our theoretical intuitions or moral and political practices concerning our uses of these words. I then propose the view that terms like 'woman' or 'man' are polysemous, arguing that it makes better sense of the significance of some forms of criticisms of mainstream gender ideology.
\end{abstract}

Keywords Moral philosophy · Philosophy of gender P Philosophy of language $\cdot$ Contextualism · Polysemy

\section{Introduction}

Is 'woman' a sex term that speakers use to talk about biological anatomy?' ${ }^{1}$ Is it a gender term that speakers use to talk about a non-biological topic, such as the roles that humans occupy in society? Mainstream use of the term suggests an affirmative answer to the former question. ${ }^{2}$ Non-mainstream use in trans communities, among trans-inclusive feminists, and elsewhere, suggests an affirmative answer to the latter. ${ }^{3}$ Call these patterns of use the usage constraint.

\footnotetext{
${ }^{1}$ My focus is on the term 'woman', but everything I say applies mutatis mutandis to the term 'man'.

2"If one asks an ordinary speaker what it is to be a woman, she/he will almost certainly answer in terms of biological traits, most likely genitalia or chromosomes. The same is true of dictionaries." (Saul 2012: 197) 3،...many speakers will sometimes use "woman" as though it is not a sex term after all - this is what they do when they refer to trans women who have not undergone reassignment surgeries as "women," a usage that seems perfectly acceptable to many of us.” (Saul 2012: 199-200)
}

N. G. Laskowski

Nicholaslaskowski@gmail.com

Extended author information available on the last page of the article 
But there is some degree of pressure not to answer both questions affirmatively, given the common idea in linguistics that all else equal, the best account of a word is the simplest one on which learning and communicating with it is easiest. ${ }^{4}$ Call this the communicative constraint. The guiding question of this paper is whether it is possible to provide an account of 'woman' that can satisfy both the usage and communicative constraints.

Several philosophers, including Saul (2012) and Diaz-Leon (2016), express varying degrees of support for a view of 'woman' that looks up to the task. The basic idea is that 'woman' has a single core profile across contexts of use, thereby satisfying the communicative constraint, but the core is also sensitive to conversational standards that shift from one context to the next, thereby satisfying the usage constraint. In Section 2, I trace the development of this contextualist view about 'woman' from Saul, who offers the view for examination, to DiazLeon, who defends a version of the view outright. In Section 3, I argue that the modifications Diaz-Leon makes to get around Saul's worries with the view sap it of the flexibility that motivates contextualism about 'woman' in the first place. My criticisms point toward an alternative view. In Section 4, I float the idea that 'woman' is ambiguous in a particular way. In addition to capturing the apparent shiftiness of the term, I argue that such an ambiguity view makes better sense of the coherence and significance of some forms of trans-inclusive feminist activism.

\subsection{Contextualism}

The term 'woman' appears to live a double life. It seems that speakers use it as a sex term to talk about biological anatomy, such as in medical offices. But it also seems that speakers use 'woman' as a gender term to talk about features of individuals that involve biological anatomy less obviously, e.g. social roles or self-identifications. One high-profile reaction to this phenomenon comes from Saul (2012: 201), who presents the following view on which 'woman' is sensitive to whichever conversational standards are salient in context.

Saul's Contextualism " $\mathrm{X}$ is a woman is true in a context $\mathrm{C}$ iff $\mathrm{X}$ is human and relevantly similar (according to the standards at work in C) to most of those possessing all of the biological markers of female sex."

This view purports to capture the conditions under which propositions expressed by uses of sentences containing 'woman' are true in context. I'll pass over the first, "human" condition on the right-hand side of the statement without comment. The second condition has two parts, the first of which concerning "standards at work", I'll discuss when I turn to Diaz-Leon's view in a moment. As for the second part of the second condition involving "possessing all of the biological markers of female sex," Saul is using 'female' as a sex term to talk exclusively about XX chromosomes, vaginal genitalia, and the like. ${ }^{5}$ (Saul 2012: 215) In addition to purporting to capture the truth-conditions of 'woman', the view on offer from Saul looks like it has the resources to explain the term's double life. Consider the following case.

\footnotetext{
${ }^{4}$ Support for the idea is also found within feminism: “...feminists need to communicate successfully both with each other and with those who are not (yet) feminists, feminists should want to avoid large-scale misunderstandings wherever possible." (Saul 2012: 197)

${ }^{5}$ I follow Saul in employing this terminology but not wading into the controversy surrounding it. For discussion, see Mikkola (2017).
} 
Case 1 Lee, who has XX chromosomes, vaginal genitalia, and the like, utters 'I'm a woman' in a discussion concerning screenings for vaginal cancer at a medical office.

Assuming it is plausible to maintain that one of the "standards at work" is the standard of having female anatomy, the view on offer from Saul predicts that 'woman' contributes a constituent concerning female anatomy to the proposition expressed by the utterance of the sentence 'I'm a woman'. That would appear to explain why 'woman' is being used as a sex term in Case 1. Now consider another case.

Case 2 Harper, who has XY chromosomes, penial genitalia, and the like, utters 'I'm a woman' in a discussion among trans-inclusive feminists.

Unlike in the previous case, none of the "standards at work" plausibly involve female anatomy in Case 2. So, the view on offer from Saul predicts that 'woman' doesn't contribute a propositional constituent involving female anatomy. That appears to explain why Harper uses 'woman' as a gender term in Case 2. ${ }^{6}$ The view on offer from Saul looks like it can explain the double life of 'woman' - it can satisfy the usage constraint.

Nevertheless, Saul stops short of endorsing contextualism about 'woman' out of concern for the predictions that the view yields in the full range of cases involving trans individuals. (Saul 2012: 203) Consider the following case.

Case 3 Ash, who possess XY chromosomes, penile genitalia, and the like, utters 'I'm a woman' in a conversation in which the dominant number of participants are traditionalists who reject any non-sex involving use of 'woman' explicitly.

Since the "standards at work" appear female anatomy-involving, Saul would worry that Ash isn't using 'woman' as a gender term - that Ash's utterance of 'I'm a woman' is false. Saul would suggest that the problem with such a result is that it "doesn't do justice to trans women's claims".7 (Saul 2012: 210) Saul is well aware that not everyone would share this concern. According to Saul, it's a concern that raises difficult issues concerning whether political, moral, or more broadly normative considerations have a role to play in philosophical semantics. For the sake of argument, I follow Saul in assuming that an adequate characterization of 'woman' should predict that Ash is using 'woman' as a gender term in Case 3.

Diaz-Leon (2016) is a fellow traveler, offering a full-throated defense of a contextualist approach to characterizing 'woman'. In particular, Diaz-Leon argues that such an approach has no trouble with cases like Case 3. In part because the dominant number of conversational participants are traditionalists in Case 3, it looks like the "standards at work" in it are sexbased, involving only XX chromosomes, vaginal genitalia, and the like. This seems to mean, as we've seen, that Ash is using 'woman' as a sex term on Saul's contextualism. However, according to Diaz, Saul's contextualism is stuck with this result in virtue of the attitudes of traditionalists. On Saul's contextualism, Ash is using 'woman' as a sex term because the view includes the attitudes of traditionalists among those features determining the "standards at

\footnotetext{
${ }^{6}$ Results like these lead Saul to frame the view as an improvement over Haslanger's (2000).

7 Arguably, a version of this case in which it is one of the traditionalist's using 'woman' instead of Ash (as in e.g. a traditionalist uttering 'You, Ash, aren't a woman') might be one in which it is even clearer that the term is being used as sex term, since on some views, speaker intentions play a big role in determining how our words are used. Feel free to substitute such a version of the case if that seems more compelling. I am using Case 3 as it is because I don't find the alternative kind of case to pose a clearer challenge, and I wish to maintain structural continuity with the other cases in this paper.
} 
work" in context. In light of this observation, Diaz-Leon suggests a path forward: replace this feature with a new one. Diaz-Leon's idea is that moral or more broadly normative considerations play a role in determining the "standards at work" in context.

Diaz-Leon's Contextualism $\mathrm{X}$ is a woman is true in a context $\mathrm{C}$ iff $\mathrm{X}$ is human and relevantly similar (according to the standards at work in $\mathrm{C}$ ) to most of those possessing all of the biological markers of female sex, where the standards at work are determined by the overall balance of normative considerations." (Diaz-Leon 2016: 251) ${ }^{8}$

This view looks like it has the resources to make the right predictions. There seem to be non-biological features in some of the cases that matter, morally speaking. For example, it is plausible to think that denying an individual's self-identification causes distress. Such denials might be thought to exhibit disrespect or risk inculcating feelings of alienation, perhaps not unlike the way in which it might be disrespectful or alienating to insist to a theist that they aren't really a believer. ${ }^{9}$ If so, then the balance of normative considerations might determine that a non-biological, gender-involving standard is "at work" in Case 3, not a biological, sex-involving standard. Plausibly, too, Ash is relevantly similar in terms of self-identification to most of those possessing all of the biological markers of female sex. Thus, Diaz-Leon's view predicts that Ash is using 'woman' as a gender term in Case 3.

Diaz-Leon's insight is that cases like Ash's don't reveal a problem for the kind of contextualist view that Saul proposes, per se. Rather, such cases bring out that the problem lies in those features determining the "standards at work" in context, i.e. the theory of salience baked into Saul's contextualism. Before evaluating Diaz-Leon's contextualism more closely, I am first going to head off a tempting objection to Diaz-Leon's account of Case 3 that will clarify an important feature of the view.

Again, Diaz-Leon's innovation is the claim that normative considerations play a role in determining the standards that are salient in context. This is what allows Diaz-Leon's view to predict that because self-identification matters morally, Ash is using 'woman' as a gender term. On broadly Humean traditions in moral philosophy, however, that which matters morally depends on our attitudes, like our desires. On such views, it could be that the desires of traditionalists, including their (say) desire to maintain mainstream linguistic practice, play a role in determining that which matters in Case 3. If so, then having female sex characteristics could matter most in that context. On this line of thought, Diaz-Leon's view predicts that Ash uses 'woman' as a gender term only on the assumption that what matters doesn't depend on attitudes. But Diaz-Leon is in no position to make such an assumption. Or so one might object.

Grant that what matters morally depends in some way on our desire-like attitudes. On this assumption, having female-sex characteristics matters, because traditionalists desire to maintain the mainstream linguistic practice of using 'woman' to talk about female sex characteristics. On this supposition, too, self-identification also matters, because Ash (say) desires not to be misgendered.

However, it doesn't follow that self-identification matters more than having female sex characteristics. Nor does it follow that having female sex characteristics matters more than self-

\footnotetext{
${ }_{8}^{8}$ Diaz-Leon offers several statements of the view that differ subtly from one another. My presentation of DiazLeon's view strives to illustrate the evolution of the view from Saul, while remaining faithful to Diaz-Leon's suggested changes.

${ }^{9}$ See Kapusta (2016).
} 
identification. For it to follow that self-identification matters more than having female sex characteristics, the desire to avoid being misgendered has to carry more moral weight. For it to follow that having female sex characteristics matters more than self-identification, the desire to maintain mainstream linguistic practice has to carry more moral weight. The claim that what matters morally depends on our desires entails neither of these further claims on its own. Thus, the question of whether morality depends on our desires is orthogonal to the question of which standard matters most in Case 3. Diaz-Leon need not worry about the tempting objection.

Nevertheless, the tempting objection does make clear that another assumption is at play in this debate. Namely, Diaz-Leon must assume that some features, e.g. self-identification, carry some moral weight, at least enough to outweigh whatever weight there might be in having female-sex characteristics some of the time. After all, that's how Diaz-Leon's view predicts that Ash uses 'woman' as a gender term in Case 3. In the next section, however, I'll argue that this assumption makes it difficult for Diaz-Leon to handle other kinds of cases and hence difficult to satisfy the usage constraint compellingly.

\subsection{Problems with Diaz-Leon's Contextualism}

In the previous section, I illustrated how Saul's contextualism accommodates the usage constraint. But I also illustrated how the view struggles to predict that, in Case 3, Ash is using 'woman' as a gender term. I then discussed how Diaz-Leon's contextualism appears to improve Saul's, by accommodating the usage constraint and predicting that Ash is using 'woman' as a gender term in Case 3.

Recall, however, that part of what motivates Saul to examine contextualism about 'woman' in the first place is its promise in accommodating cases in which speakers use 'woman' as a gender term and other cases in which speakers use it as a sex term. Diaz-Leon never circles back to discuss the latter. The main lesson of this section will be that Diaz-Leon's view has difficulty accounting for such cases. While Diaz-Leon's view has the benefit of making the right prediction about Ash, it has the cost of failing to satisfy the usage constraint. Or so I'll now argue.

Consider another example.

Case 4 Jo, who has XY chromosomes, penial genitalia, and the like, utters 'I'm a woman' while visiting a friend at a crisis center offering counseling to victims of rape, the overwhelming majority of whom at the center are female.

Mainstream usage of 'woman' suggests that speakers use it as a sex term in some scenarios. Case 4 is put forward as such a scenario - Jo is using 'woman' as a sex term. ${ }^{10}$ Suppose, however, that Jo is so fed up with being misgendered that they would become severely

\footnotetext{
${ }^{10} \mathrm{I}$ am not claiming that it is impossible to use 'woman' as a gender term in crisis centers. Indeed, YWCA Spokane, which offers domestic violence services, states admirably and explicitly that they "will never turn a person away based on gender identity, sexual identity, sexuality, race, or ethnicity" (https://ywcaspokane.org/hudproposal/). In such a context, which I've chosen, admittedly, based on my anecdotal experience, it's plausible that 'woman' is used as a gender term. But not all contexts are alike. To take another actual but less personally relevant example, Vancouver Rape Relief \& Women's Shelter states explicitly that "Trans people deserve and must live in safety, and have the equal rights and opportunities that are promised to us all. While some of our core services are not open to people who do not share our life experience of being born females and raised as girls into our current womanhood, we have a collective commitment to see to the safety anyone who calls our crisis line, including trans people. (emphasis mine, https:/www.rapereliefshelter.bc.ca/learn/resources/who-we-serve)". Plausibly, 'woman' is used as a sex term in such a context. Case 4 is put forward as a case where the center is more like the Vancouver shelter than the one in Spokane.
} 
depressed and hence suicidal if 'woman' were not being used as a gender term. ${ }^{11}$ Plausibly, self-identification would then carry the most moral weight. After all, Jo's life in part depends on it. Because features that carry moral weight determine which standards are salient in context on Diaz-Leon's view, and because self-identification is a non-biological feature, Diaz-Leon's view predicts that a non-biological standard is salient in Case 4. Thus, Diaz-Leon's view predicts that Jo is using 'woman' as a gender term, not a sex term. That's a problem.

This might strike readers as too quick, leaving them with the impression that something must be awry in Case 4. But Case 4 is no one-off counterexample. It is the result of a simple recipe. Take any case in which 'woman' is being used plausibly as a sex term. Arrange the features such that self-identification matters. Further arrange the features such that selfidentification matters more than any biological feature. The result will be that a nonbiological standard is salient. Thus, speakers will use 'woman' as a gender term.

Getting around this problem requires that self-identification carries enough moral weight to make a non-biological standard salient in cases like Case 3, but not so much moral weight as to make such a standard salient in cases like Case 4. That's too fine a line to walk. The point here is that, on Diaz-Leon's view, 'woman' is used as a gender term in more cases than is compatible with the usage constraint. ${ }^{12}$

In light of this line of criticism, it is natural to wonder whether Diaz-Leon's view is a genuine form of contextualism rather than a form of invariantism in disguise, in which no part of the term shifts across contexts. Consider paradigmatically contextual terms like 'I' or 'me'. We use these terms to talk about different speakers in different contexts. In fact, every context with a different speaker yields a different topic. Compare the number of contexts with different speakers to the number of contexts in which self-identification is not very morally significant. It's no contest. But just as we would begin to doubt whether 'I' or 'me' are contextual if we only ever used them to talk about anyone besides me, the author, we should doubt that 'woman' is contextual on Diaz-Leon's view for similar reasons.

In reply, Diaz-Leon could insist that 'woman' is more analogous to terms like 'I' than it seems on a first pass. Sure, Diaz-Leon might say, because the world is such that selfidentification matters morally, 'woman' is used as a gender term in a surprising number of cases. And sure, Diaz-Leon might also say, the world is such that 'I' is used in a huge variety of ways, e.g. as a Jennifer-Saul-term, Esa-Diaz-Leon-term, Angela-Merkel-term, SerenaWilliams-term and so on. But, Diaz-Leon might then say, the source of this difference between 'woman' and 'I' is the nature of our world, not the nature of these words. In principle, the world could be such that we use 'woman' to talk about a huge variety of different standards in different contexts, perhaps equally as many standards as there are speakers occupying contexts. In other words, 'woman' and 'I' differ only superficially. Or so Diaz-Leon might say.

Grant the point that 'woman' and 'I' owe their differences to worldly features that can be ignored. Still, on Diaz-Leon's view, there is a real difference between the nature of 'woman' and 'I', owing to the role that normative considerations play in uses of the former. Normative principles are widely held to be metaphysical necessary if true, e.g. necessarily there's an obligation to treat persons with

\footnotetext{
${ }^{11}$ By using details involving crisis centers and depression-induced suicides in philosophical examples, I risk implicating that I do not take these matters seriously. Allow me to cancel that possible implicature. Sexual violence, depression, and suicide are all issues that hit close to home. I take these morally significant issues deeply seriously.

12 Over the course of developing my objection, I came to learn that Bettcher (2017) raises a similar worry with Diaz-Leon's view. But Bettcher does so in the context of a survey article, and hence only has the space therein to gesture toward the problem. My presentation can be thought of as expanding on Bettcher's compressed insight.
} 
respect if there's an obligation to treat persons with respect at all. If that's right, then there will be a number of worlds that are such that e.g. misgendering amounts to a form of disrespect, and hence a number of worlds in which there's an obligation not to misgender. In other words, there will be a number of worlds in which non-biological standards are salient, where 'woman' is used as a gender term. But then it seems like 'woman' is far less flexible than 'I'. Thus, even granting the imagined response from Diaz-Leon, 'woman' seems different on Diaz-Leon's view from paradigmatically contextualist terms like 'I'.

There is another response to these concerns with Diaz-Leon's view. It's no problem, one might claim, that Jo is using 'woman' as a gender term in Case 4. Yes, typical cases involving medical scenarios or crisis centers are ones in which biological features carry the most moral weight. But Case 4 isn't typical - it's a case where non-biological features carry the most moral weight, in virtue of the fact that Jo would become strongly upset upon being misgendered. Accordingly, one might think, there's no problem with making an exception for Case $4 .{ }^{13}$

On one way of understanding this response, it's calling into question the usage constraint. Because any adequate characterization of 'woman' must accommodate the usage patterns of the term, such patterns place constraints on an adequate characterization of 'woman'. The pattern at issue in this paper is that speakers sometimes use 'woman' as a sex term and sometimes use it as a gender term. Case 4 is put forward as an illustration of cases of the former type. The response above call this into question - it denies that Case 4 is one in which the speaker uses 'woman' as a sex term.

Keep in mind, however, that Case 4 is supposed to be illustrative. Even if it turns out to be a case in which the speaker is using 'woman' as a gender term, there will still be other, similar cases in which speakers are using 'woman' as a sex term where the non-biological features are such that Diaz-Leon's view predicts otherwise. Again, Case 4 follows a recipe. One could go through every case generated by the recipe, arguing that each of them are actually cases in which speakers are using 'woman' as a gender term. But doing so would seem to amount to a flat-out rejection of the usage constraint, and the start of an entirely different debate.

In a last-ditch effort, one might grant these worries but insist that they're not problems, because Diaz-Leon's view is put forward as a revisionary one. While it's true that Diaz-Leon's contextualism makes predictions that are at odds with the usage constraint, one might say, it's also true that speakers should put in some effort to use 'woman' in the way the view predicts we've been using it from here on.

Three comments: Firstly, Saul entertains the idea that we should consider contextualism as a revisionary proposal. (Saul 2012: 402). In response, Diaz-Leon is explicit about the nature of the project:

"In response, I want to argue that we can see this point [Saul's claim that "disagreements over who counts as a woman are simply not to be settled by appeal to the facts of language"] also as a genuinely linguistic point, that is, as a descriptive claim about the (actual) meaning of woman, not just as a revisionary proposal about how the term woman should be used, given our moral and political aims...I want to argue that it is also possible to provide moral and political considerations that are relevant with regard to the descriptive project of finding out the meaning of woman." (Diaz-Leon 2016: 248249, emphasis mine)

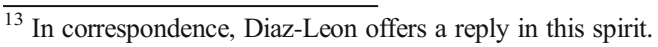


Of course, however, while Diaz-Leon might not conceive of the project as revisionary, it nevertheless could be that it's best conceived of as such. This brings us to the second response, which is more concessive. Yes, it very well could be that the prospects for contextualism are best when seen through the revisionary lens. This point is exactly right, and it's one to which I'll return toward the end of this paper. However, and this is the third response, it's also worth noting that contextualism doesn't, on the face of it, sit well with the revisionary goal of changing how 'woman' is used. For one of the central insights of contextualism is that speakers have less of a say, as it were, in how words are used, in virtue of the fact that context does a lot of the heavy lifting. ${ }^{14}$

\section{Toward an Alternative Account}

Recall, I set out to determine whether contextualist views of 'woman' can satisfy the usage and communicative constraints. So far, however, I have said very little about the latter. This is in a way unsurprising. For one of the main selling points of contextualist views, generally speaking, is that they associate a single component with words across contexts, making the communicative constraint satisfiable rather straightforwardly. As such, the question taking center stage has not been whether contextualist views like Saul's and Diaz-Leon's can satisfy the communicative constraint. Rather, the question has been whether they can satisfy the usage constraint. In the space remaining, I explore the following idea: starting with views that have an easy time with the communicative constraint, like contextualism, might end up occluding a promising route to satisfying both constraints. Perhaps if we start with views that seem to have an easier time with the usage constraint, we'll then end up with a view that satisfies both constraints.

From this perspective, the obvious alternative is the view that 'woman' is ambiguous - it has a sex-involving meaning or a gender-involving meaning, not a single meaning that determines different semantic values in different contexts. On such a view, speakers sometimes use 'woman' to communicate the sex-involving meaning but sometimes use it to communicate the gender-involving meaning. This view makes the usage constraint a piece of cake.

But it also faces an awkward difficulty: the communicative constraint tends to motivate philosophers to minimize ambiguities whenever possible. Take a word like 'good' from ethics, for example. Rarely in everyday use, it seems, do speakers have any trouble understanding what people mean with this term. This would be hard to square if 'good' were ambiguous, however. So, ethicists tend to conclude that 'good' and other ethically significant terms like it are not ambiguous. ${ }^{15}$

\footnotetext{
${ }^{14}$ Another reply that Diaz-Leon suggests in correspondence distinguishes between normative considerations that are of the right kind to fix which standards are salient and those that aren't. Diaz-Leon could then claim of Case 4 that while Jo's risk of suicide from misgendering is a serious moral concern, it's the wrong kind of moral concern to affect which standard is salient in context. It's a normative consideration that can be screened off in the theory of contextual salience.

But it seems that such a response makes Diaz-Leon's view hostage to a solution to an even harder question the question of how to distinguish reasons of the right and wrong kind. In other words, the problem with this response is that it involves jumping from the pan to the fire. See D'Arms and Jacobson (2000) and Rabinowicz and Rønnow-Rasmussen (2004) to get a sense of the difficulty of the issue.

${ }^{15}$ See especially Finlay (2014). Ziff (1960) and Thomson (1992), among others, also counsel caution before claiming that 'good' is ambiguous.
} 
Recently, however, the idea that there are different kinds of ambiguities, some better than others with respect to preserving the appearance that speakers often succeed in communicating with one another, has been garnering attention in philosophy. ${ }^{16}$ A term that is ambiguous has multiple meanings. That much is familiar. Less familiarly, a term can be ambiguous in the sense that it is homonymous, having multiple unrelated meanings, or it can be ambiguous in the sense that it is polysemous, having multiple related meanings.

Standard examples of terms that are homonymous include 'bank'. This term has one meaning involving financial institutions and another involving rivers. Compare the homonymous ambiguity of 'bank' to the polysemous ambiguity of 'cut'. The term 'cut' has a meaning involving incision, another involving turning sharply, passing objectionably in a que, insulting someone, and so on. The principle difference between 'bank' and 'cut' is that the meanings of the former appear completely unrelated to one another, while the meanings of the latter all seem to have something to do with the idea of division. Such relations appear to preserve our ability to communicate successfully - it's perhaps rarer to ask for clarification when an interlocutor uses a word like 'cut' than it is when they use a word like 'bank'. The point is that there need not be reasons to avoid an ambiguity approach to characterizing a term, and so there need not be reasons to avoid an ambiguity approach to 'woman'. ${ }^{17}$

Of course, however, that there might not be any communicative constraint-based reasons against embracing polysemous ambiguity for 'woman' doesn't imply that there are any reasons favoring one. But it's not hard to find such reasons. Consider the etymology of 'woman'. Large groups of speakers have begun using it clearly as a gender term recently. This seems to imply that its meaning descends historically from an original one, which is interesting, because historical connectedness is one of the hallmarks of polysemy. ${ }^{18}$

Perhaps even more interestingly, a polysemous ambiguity account of 'woman' appears to have an important advantage over versions of contextualism like Diaz-Leon's. Over the course of defending contextualism, Diaz-Leon issues the following criticism of Bettcher (2013), who holds a related view ${ }^{19}$ to the one I am floating:

“...if we adopt a multiple-meaning account [or, relatedly, a polysemy account], we are accepting the existence of certain meanings that are exclusionary. That is, we will understand some speakers in some contexts as using woman in a way that is exclusionary...And this will have the consequence that whether (some) trans women count as women in some contexts will depend on which meanings are at issue...And this seems problematic.” (Diaz-Leon 2016: 254, original emphasis)

It's true that there will be some meanings of 'woman' that are exclusionary on the view that the term is polysemous. However, and this is key, that's exactly what should be expected on a

\footnotetext{
${ }_{16}$ Polysemy receives plenty of attention in linguistics. See Vicente and Falkum (2017) for an overview.

${ }^{17}$ Leslie (2015) suggests a similar view explicitly, arguing in the context of the debate regarding generics that it's the best way to make sense of them.

${ }^{18}$ See Viebahn and Vetter (2016)

${ }^{19}$ Bettcher (2013: 240-244) argues that 'woman' has both "dominant" and "resistant" meanings, which map, roughly, onto the polysemous view of 'woman' floated in this paper, where 'woman' has a meaning in mainstream society that is different from the meaning it has among trans and trans-inclusive feminist communities. This is why the views are similar. Though similar, I hesitate to characterize Bettcher's view as polysemic not only because Bettcher doesn't, but also because some of what Bettcher says suggests that speakers can "reject" as "false" attributions of terms with meanings for which they are against, implying that speakers have a degree of linguistic control that is in tension with my understanding of polysemic views. Comparing these views fully requires more space than is available in this paper.
} 
realistic portrayal of the current socio-political state of the world. It's hard to deny that mainstream usage of 'woman' often excludes trans individuals. That's part of the reason there even exists trans-inclusive feminist activism. It's precisely because so many speakers in the world use the excluding senses of 'woman' that trans-inclusive feminist activism has teeth. Trans-inclusive feminist activism would make little sense if everyone were already using 'woman' in a trans-inclusive way.

This way of understanding the significance of trans-inclusive feminist activism might seem to imply that philosophers should think about cases like Case 3 differently, where Ash uses 'woman' as a sex term in part because they are surrounded by traditionalists. Indeed, it does have this implication. Saul worries that in cases like Ash's, the contextualist view they explore is morally problematic because it predicts that Ash is using 'woman' as a gender term. Partially as a result, Saul abandons the view. Diaz-Leon shares the worry, setting out to resolve it semantically, by developing a normative version of contextualism predicting that Ash is using 'woman' as a gender term. Saul and Diaz-Leon are right to worry that their views predict that Ash is using 'woman' as a sex term, but wrong to think that the remedy is to find a semantic view that doesn't have this prediction. That's a way of denying that Ash's situation was really ever problematic, and hence a way of saying that there wasn't to begin with any trans-inclusive feminist work to be done in such situations. But there was and is such work - it's just more moral or political than semantic.

On a polysemic picture, one of the goals of trans-inclusive feminist activism is to agitate for broader use of the more inclusive senses of 'woman' available. To touch an earlier point, the resulting picture is a revisionary or engineering one in a particular sense. The goal isn't to engineer a concept or word in the sense of introducing a new one. That's already happened, as use of it among trans and trans-inclusive feminist communities indicate. ${ }^{20}$ Instead, at least from the perspective of trans-inclusive feminist activism, the goal is to make the inclusive use of 'woman' more mainstream. ${ }^{21}$

It might be said in response that the polysemy view doesn't have the advantage of making better sense of trans-inclusive feminist activism than Diaz-Leon's contextualism. Suppose Diaz-Leon were to supplement their brand of contextualism with resources broadly available to semantic externalists, on which words, roughly, mean what they do in virtue of referring to what they do, and they refer to what they do in virtue of being causally connected via chains of use to baptismal events introducing them or in virtue of being connected deferentially to use among

\footnotetext{
${ }^{20}$ In a recent paper, Bogardus (forthcoming: 23 ) argues, among other things, that attempts to provide a transinclusive account of 'woman' that depend on the possibility of conceptual engineering are either "impossible to complete due to unintelligibility" or "impossible to complete, at least in a way that includes all or even most trans women". There isn't enough space to investigate Bogardus' argument fully. But focus on the first disjunct. Note, trans individuals and trans-inclusive feminists engaging in conceptual engineering, such as Jenkins (2016), following Haslanger (2000), use 'woman' in an inclusive sense. Note, too, that when they do, they understand each other. This simple fact counts strongly against any argument for the "unintelligibility" of trans-inclusive uses of 'woman'.

Moreover, Bogardus takes his argument to show that the first disjunct is true because "Ameliorative Inquiry inevitably introduces ambiguity - new homonyms - and thereby results in merely verbal disputes, a change of subject" (my emphasis). Bogardus doesn't acknowledge the possibility of polysemy. With polysemy in view, it looks possible to engage in at least something close to ameliorative inquiry in Haslanger's sense without "introducing [homonymous] ambiguity".

${ }^{21}$ Dembroff (Forthcoming) arrives at conclusions in the same spirit from a different starting point.
} 
communities of experts. Details aside, the upshot could be that mainstream use of 'woman' is maximally inclusive but speakers aren't aware of it. ${ }^{22}$ If so, then it could be that one of the organizing goals of trans-inclusive feminist activism is to make everyone aware that they're using the word 'woman' inclusively already. Perhaps that's the best way to understand the significance of trans-inclusive feminist activism, instead.

This response raises a number of interesting issues that there isn't space to explore fully. Nevertheless, there are at least two reasons - one specific to the debate and one more general to think it doesn't succeed in showing that Diaz-Leon's view of 'woman' makes better sense of trans-inclusive feminist activism surrounding it than a polysemous view. Suppose speakers are using 'woman' in a maximally inclusive way on a version of Diaz-Leon's view that is supplemented with externalist resources. If so, and this is the first specific reason, then it's hard to see why Saul and Diaz-Leon would ever have been worried about Ash's use of 'woman' in cases like Case 3. But even if they're mistaken to worry, as I've suggested above, it's not hard to see why they're worried.

Moreover, and this is the second more general reason, the English language is shot through with words that are polysemic. ${ }^{23}$ Though the issue is underexplored, the fact that the English language, and most languages, for that matter, contain so many polysemic words seems to be in tension with strong forms of semantic externalism. Combining strong forms of semantic externalism with the fact that the English language contains so many polysemic words seems to suggest an implausible degree to which English speakers are ignorant or in error.

\section{Conclusions}

One of my main aims in this paper has been to show that Diaz-Leon's version of contextualism predicts that we use 'woman' much more often as a gender term than as a sex term, in a way that is at odds with the usage constraint. Along the way, I also put forward the claim that we should be open to ambiguity-based alternatives to contextualism, like a polysemy account of 'woman'. Admittedly, it's easy to walk away from these claims with the impression that the central upshot of this paper is that the whole family of contextualist views about 'woman' is hopeless.

But that's not quite right. As it happens, the jury is still very much out on how to understand the precise differences between contextualism and polysemy. Indeed, some philosophers suggest that there isn't much daylight between polysemy and contextualism. ${ }^{24}$ It could be, then, that in defending a polysemic view of 'woman', I've defended a kind of contextualism. Moreover, I argued that attempts like DiazLeon's to make facts about the contextualist semantics of 'woman' line up with facts about how we ought to treat each other morally, by building morality into semantics,

\footnotetext{
$\overline{22}$ See Kripke (1972) and Putnam (1975) for canonical treatments. See Mallon (2017) for a recent discussion of externalist views of social terms, errors in use, and other related issues.

${ }^{23}$ As Fogal (2016) points out, “... polysemy is utterly pervasive in natural language... and it affects both content and function words. It also tends to be both systematic and productive, with similar patterns of polysemy applying to similar words across many languages...the default hypothesis for pretty much any ordinary noun, adjective, or verb should be that it is polysemous, and thoroughly so."

${ }^{24}$ See Recanati (2017).
} 
come up short. But not all contextualist views build morality into semantics. The contextualist view that Saul floats doesn't. So, I can also be read as defending nonnormative versions of contextualism like Saul's; at least, I can be read as offering such a defense, so long as what's really going on in cases like Ash's in Case 3 is appreciated - Ash's context is such that 'woman' is being used as a sex term now, but trans-inclusive feminist activists are working to create a society in which that's not the case later.

Whether a non-normative contextualism or polysemy ambiguity theory for 'woman' is best, it's worth emphasizing that such views are promising in part because they don't incorporate moral conditions into semantics. Instead of tasking semanticists with sorting out how it could be that the semantic facts line up with the moral facts, we should ask moral philosophers, including, especially, trans-inclusive feminist moral philosophers, what we ought to do in light of these facts failing to line up.

Acknowledgments Thanks to Robin Dembroff, Esa Diaz-Leon, Nathan Robert Howard, Sofia Huerter, Daniel James, Jennifer Saul, and Daniel Wodak for constructive feedback. Thanks also to audiences at The Nature and Significance of Social Kinds Workshop at the Institute for Advanced Studies in the Humanities in Essen, Human Kinds Workshop at KU Leuven, the 2018 Rocky Mountain Ethics Congress, the Philosophical Anthropology and Ethics Research Group seminar organized by Neil Roughley at Duisburg-Essen Universität, and the British Society for Ethical Theory.

\section{References}

Bettcher, T. 2013. "Trans Women and the Meaning of "woman."' In The Philosophy of Sex, ed. Nicholas Power, Raja Halwani, and Alan Soble. Lanham, Md.: Rowman and Littlefield

Bettcher T (2017) Trans feminism: recent philosophical developments. Philos Compass 12(11):e12438

Bogardus, T. (forthcoming). "Some Internal Problems with Revisionary Gender Concepts". Philosophia:1-21

D’Arms J, Jacobson D (2000) Sentiment and value. Ethics 110(4):722-748

Dembroff, R. Forthcoming. "Real talk on the metaphysics of gender". Philos Top

Diaz-Leon E (2016) Woman as a politically significant term: a solution to the puzzle. Hypatia 31(2):245-258

Finlay S (2014) Confusion of tongues: a theory of normativity. Oxford University Press, Oxford

Fogal D (2016) Reasons, reason, and context. In: Lord E, Maguire B (eds) Weighing reasons. Oxford University Press

Haslanger S (2000) Gender and race: (what) are they? (what) do we want them to be? Nous 34(1):31-55

Jenkins K (2016) Amelioration and. Inclusion: Gender Identity and the Concept of Woman 126(2):394-421

Kripke, S. 1972/1980. Naming and necessity. Cambridge, Massachusetts, Harvard University Press

Leslie S (2015) "Hillary Clinton is the only man in the Obama administration": dual character concepts, generics, and gender. Analytic Philosophy 56(2):111-141

Mallon R (2017) Social construction and achieving reference. Noûs 51(1):113-131

Mikkola, M. 2017. "Feminist perspectives on sex and gender". In The Stanford Encyclopedia of Philosophy, ed. Edward Zalta. October 2017 edition. http://plato.stanford.edu/

Putnam H (1975) “The Meaning of "Meaning".” Mind, Language and Reality: Philosophical Papers. New York, Cambridge University Press 2:215-271

Rabinowicz W, Rønnow-Rasmussen T (2004) The strike of the demon: on fitting pro-attitudes and value. Ethics 114(3):391-423

Recanati F (2017) Contextualism and polysemy. Dialectica 71(3):379-397

Saul J (2012) Politically significant terms and philosophy of language: methodological issues. In: In Out from the Shadows: Analytical Feminist Contributions to Traditional Philosophy, ed. Oxford University Press, Sharon Crasnow and Anita Superson. Oxford

Kapusta S (2016) Misgendering and its moral contestability. Hypatia: A Journal of Feminist Philosophy 31(3): 512-519

Thomson J (1992) On some ways in which a thing can be good. Soc Philos Policy 9(2):96-117 
Vicente, A. \& Falkum, I.L. 2017. "Polysemy". In Oxford Research Encyclopedia of Linguistics. Ed. Mark Aronoff. New York: Oxford University Press

Viebahn E, Vetter B (2016) How many meanings for 'may'? The case for modal polysemy. Philosophers' Imprint 16

Ziff P (1960) Semantic analysis. Cornell University Press, Ithaca, NY

Publisher's Note Springer Nature remains neutral with regard to jurisdictional claims in published maps and institutional affiliations.

\section{Affiliations}

\section{N. G. Laskowski ${ }^{1}$}

1 California State University, Long Beach Philosophy Department, 1250 Bellflower Blvd, 90840-2408, Long Beach, CA, USA 